\title{
Cuerpo y sexualidad desde una teología crítica y emancipadora
}

\author{
Daniel Pacheco H.*
}

\author{
Recibido: Julio 2011 • Aceptado: Setiembre 2011
}

\section{RESUMEN}

El objeto central de análisis de este artículo es el cuerpo humano, especialmente en su dimensión integral de la sexualidad. En primer lugar, se hará un breve recorrido histórico sobre algunas importantes ideas sobre el cuerpo y la sexualidad desde la teología y la tradición filosófica occidental. En un segundo punto, se reseñará los puntos polémicos de la enseñanza actual del magisterio católico y de otras tradiciones cristianas sobre el cuerpo y la sexualidad. En la tercera parte analizaremos la visión del cuerpo en la modernidad, y varios problemas que sufren los cuerpos de hombres, mujeres, niños y jóvenes en el mundo actual. Por último, se ofrecerá una propuesta de equilibrio desde una teología que busque la liberación y el desarrollo humano integral desde las dificultades del ser humano hoy.

Palabras clave: Cuerpo humano, Sexualidad, Teología crítica, Filosofía occidental, Magisterio católico, Modernidad, Desarrollo humano integral.

\begin{abstract}
The main objective of the analysis in this article is the human body, especially in its integral dimension of the sexuality. First, it will be done a brief historical tour about the main ideas of the body and the sexuality from the theology and philosophical occidental tradition. Second, it will be shaped the main points of the current education of the catholic and Christian traditions about the body and the sexuality. Third, we will analyze the vision of the body in the modernity, and several problems which the men, women, children, and younger's bodies suffer in the current world. Finally, it will be offered a proposal of the balance since a theology which looks for the release and the human integral development from the difficulties of the human being nowadays.
\end{abstract}

Key words: Human body. Sexuality. Critical theology. Occidental Philosophy, Catholic teaching. Modernity. Integral human development.

\footnotetext{
* Posee un Bachillerato en Antropología Social de la Universidad de Costa Rica y una Maestría en Teología por parte de la Universidad Estatal a Distancia. Sus investigaciones se centran en el campo de la teología moral y en el desarrollo humano de comunidades vulnerables.
} 


\section{Introducción}

En el relato La colonia penitenciaria, Franz Kafka se nos ofrece una pertinente metáfora de la situación que atraviesan muchos seres humanos hoy, particularmente en su dimensión corporal. En el cuento, un condenado a muerte va a recibir un terrible castigo por violar una ley que no le fue explicada, por medio de una máquina cuyo proceso es más importante que la vida humana o que la justicia y los derechos humanos.

La máquina de la colonia penitenciaria, que inflinge castigos incomprensibles sobre el cuerpo, se mantiene gracias a viejas leyes incompatibles con las auténticas exigencias humanas, semejante a muchas estructuras de pensamiento $\mathrm{y}$ poder obsoletas que siguen gobernando este mundo, aún siglos después de que se anunciara que la razón gobernaría con justicia. La metáfora kafkiana es de especial interés para el presente ensayo porque nos encontramos con un aparato que marca la carne, el cuerpo de un individuo que clama al menos por una explicación o por una oportunidad de respuesta ante la realidad que se presenta.

En este estudio, identificaremos cómo a lo largo de la historia y en la actualidad existen varias "máquinas kafkianas" o conjuntos de ideas en torno al cuerpo y en general en torno al ser humano, para proponer un balance justo sobre la situación del ser humano hoy, y las exigencias que éste hace a la teología hoy actualmente.

Este ejercicio no pretende ser solamente una crítica contra las tradiciones y lo antiguo. Aún en nuestra metáfora inicial del relato de Kafka, las ideas y visiones de mundo del viejo general que ejerce el castigo no son condenadas tanto por su contenido, sino por su método. Así pues, descubriremos el valor que la tradición cristiana ofrece sobre algunas dimensiones del cuerpo, y veremos cómo es necesario que esta tradición dialogue y busque mutua iluminación con las nuevas exigencias y los nuevos contextos del mundo actual.

Al tratar el problema del cuerpo, es posible ser tachado de materialista, algunos quizá incluso -en un claro eclipse conceptual- calificarán la legítima preocupación por lo corporal como hedonismo o parcialidad sobre un aspecto de lo humano‥ Al hablar aquí del

1. Desde los antiguos filósofos clásicos, entre ellos Demócrito y Epicuro, el materialismo es una correinte filosófica opuesta al idealismo, que abarca no sólo una visión del mundo, sino también la ética, la política, la economía y cultura de la sociedad. En el siglo XIX alcanza un repunte con los aportes de Marx y de Engels, sobre todo en la crítica económica, política e histórica de la sociedad. Para ampliar en los aspecos éticos y 
cuerpo no pensamos en inmediatez, hedonismo o materialismo, sino que deseamos enfatizar una dimensión básica del ser humano, que junto con lo psíquico, lo biológico, lo social y lo espiritual, conforman al ser humano completo.

Más aún, en determinados momentos esta dimensión alcanza especial relevancia, como cuando nos referimos al hambre física real de miles de millones de personas en el mundo actual, la cosificación de la mujer prostituida, en la falta de movimiento de los presos, en el movimiento obligado de los migrantes, y muchas otras situaciones.

En la primera parte de este ensayo, haremos un breve recorrido histórico en torno a algunas importantes ideas sobre el cuerpo y la sexualidad desde la teología y la tradición filosófica occidental, y descubriremos que existe un tema transversal en todo esto que sigue vigente hasta hoy: la visión de la mujer como peligrosa, opuesta a una supuesta naturaleza humana "auténtica masculina" y junto con ella el velo de silencio y negatividad ejercido sobre la sexualidad.

En un segundo punto, veremos los aspectos polémicos de la

políticos se recomiendan las obras Gilles Lipovetsky, La era del vacio, y la de Raymond Aron, Dimensiones de la conciencia histórica.

2. Es pertinente recordar que según algunas enseñanza actual del magisterio católico y de otras tradiciones cristianas sobre el cuerpo y la sexualidad, descubriendo el valor de sus enseñanzas, y reflexionando sobre aquellos puntos que parecen no responder adecuadamente a muchas exigencias del humano hoy.

En la tercera parte analizaremos la visión del cuerpo en la modernidad, y varios problemas que sufren los cuerpos de hombres, mujeres, niños y jóvenes en el mundo actual.

Por último, intentaremos ofrecer una propuesta de equilibrio desde una teología que busque la liberación y el desarrollo humano integral desde las dificultades del ser humano hoy en América Latina, que enfrenta dos problemas distintos pero relacionados: por un lado la pobreza y la falta de oportunidades que sufren millones de habitantes; por otro lado el materialismo, egoísmo y visión parcial sobre el cuerpo y el ser humano y su cuerpo como mera carne vacía, como mercancía.

En cuanto al método por utilizar, haré una apuesta doble, con epistemologías que recorren caminos diferentes pero con un mismo fin. Se empleará la tradición teológica histórico-crítica para el análisis de determinados fragmentos bíblicos y las enseñanzas de los padres de la Iglesia, para posteriormente acercarnos al método teológico pastoral 
latinoamericano estipulado en Puebla y retomado en Aparecida: ver, juzgar, actuar. Lo anterior nos permitirá inducir las exigencias que la realidad plantea a la teología.

A lo largo del texto lanzaré preguntas relevantes para nuestra realidad actual latinoamericana y para construir una teología que libere no sólo al cuerpo y la sexualidad, sino al género humano en todas sus dimensiones integrales.

\section{Una visión crítica de la historia del cuerpo y la sexualidad y su relación con el cristianismo}

Ubiquémonos por un momento en los orígenes de la historia humana, en esa dimensión mítica de la cual se nutre toda cosmovisión. Al pensar en los orígenes de nuestra visión religiosa actual sobre el cuerpo y lo sexual, debemos retroceder a los grandes mitos fundantes sobre la tierra, la mujer, la fecundidad y la fertilidad. El gran historiador de las religiones Mircea Eliade señala que desde las cosmogonías griegas, se señala que Gaia, la Tierra, se autofecunda para dar a luz a un ser igual a ella con el cual poder unirse, dándose así la dualidad primigenia cielo-tierra, donde la tierra es madre y el cielo padre. Muchos rituales y mitologías de todo el mundo ubican a la tierra como madre, como fecundadora y dadora de la corporeidad, del "homo-humus" donde permanece el cuerpo tanto en la vida como después de la muerte. La tierra no sólo está viva y es fecunda, sino que también es la dadora de vida. ${ }^{2}$ Nótese quw en estas referencias míticas sobre la fecundidad, lo terreno, la fertilidad, se revisten de un profundo carácter femenino. Eliade señala que muchas culturas hacen un vínculo simbólico dual entre la tierra arada y la vagina de la mujer; en relación con el arado y el falo del varón (Eliade 1972:220-239).

Sin embargo, creo que no es necesario analizar antiguos mitos fundantes de las cosmovisiones para descubrir que lo femenino siempre se ha asociado a lo sexual, lo corpóreo, la fertilidad. Hoy, la publicidad, los medios de comunicación, el cine, y la televisión siguen arrojando sobre lo femenino esa excesiva carga explícita de sexualidad, corporalidad, morbo, que es oculto y al mismo tiempo deseable, secreto pero reconocido, prohibido pero buscado por todos.

teorías paleontológicas y antropológicas, las primeras representaciones de divinidades en el paleolítico y en el neolítico son de mujeres, todas ellas con rasgos de embarazos, amamantamiento y fecundidad. De ahí se puede derivar que, probablemente, el concepto humano de Dios nació siendo mujer y después debido al reforzamiento de modelos patriarcales, las imágenes de Dios se volvieron masculinas. Véase Rodríguez, P. (2000) Dios nació mujer. Ediciones B, Barcelona.

3. La tradición sacerdotal (abreviada P) es, de 
Así pues, si queremos esbozar una historia sobre lo corporal y lo sexual, debemos ubicar un hilo conductor en lo femenino, en la historia de la mujer. La autora Agacinski precisamente hace este recorrido, donde demuestra que en los últimos 2000 ó 3000 años, lo femenino ha sido frecuentemente asociado a lo sexual, terrenal, corporal, mientras que el varón, prototipo de la creación, es y se asocia a la razón, lo etéreo, lo metafísico.

La denuncia que nos plantea Agacinski en su obra La metafísica de los sexos no es una mera anécdota. Ésta descubre que la producción intelectual de toda nuestra tradición judeocristiana, base de nuestra cosmovisión, ha sido pensada, redactada e interpretada por varones, y esto le da un carácter especial a la antropología filosófica, donde el varón será siempre el Yo, el que se asimila al género humano. Durante siglos y hasta hace pocas décadas, "hombre" era sinónimo de nuestra especie, sin que mediara conflicto político o lingüístico alguno:

... hasta ahora siempre se ha pensado en el hombre genérico como sujeto masculino. Todos los términos neutros como el sujeto en general o el individuo indeterminado no hacían si no ocultar la situación y el punto de vista sexuado del filósofo, haciendo pasar por universal el sello de lo masculino en el pensamiento... decir que la filosofía ha sido masculina no es solamente constatar el hecho de que fuera inventada y escrita por hombres, si no detectar en ellas las huellas de un régimen de pensamiento centrado en lo masculino o, dicho de otro modo, androcentrado, régimen unas veces explícito y otras veces implícito (Agacinski 2005:5).

Al leer estas reflexiones de Agacinski, me es imposible dejar de pensar que muchas otras formas de humanidad, además de la mujer, han sido excluidas de la conformación del pensamiento cristiano, como lo son la juventud, la niñez, o las personas con colores de piel oscuros. El cuerpo solamente blanco, masculino y adulto, fue durante siglos el único autorizado para ofrecer formas de ver el mundo.

Agacinski nos ofrece un claro panorama sobre el papel de la mujer en la tradición del Antiguo y el Nuevo Testamento, que se centra en los dos prototipos de mujer establecidos y contrapuestos: Eva y María.

En el Antiguo Testamento, encontramos dos relatos de la creación del mundo y el género humano. El de la tradición sacerdotal $^{3}$, posterior cronológica y

acuerdo con la Hipótesis documentaria, la más reciente de las cuatro fuentes a partir de las cuales se escribieron los libros del Tanaj (para los judíos) o Antiguo Testamento 
literalmente, establece la creación de la mujer a partir de la costilla del hombre, posee mucha más relevancia en la construcción del edificio androcentrado de la tradición judeocristiana que el relato primero de la tradición Yahvista ${ }^{4}$ donde ambos géneros se crean al mismo tiempo. Para salir de este embrollo literario, que parece ofrecer dos opciones excluyentes dentro del relato del Génesis, Agustín estipula que la unicidad señalada en el primer relato no toca lo corporal y se refiere solamente a lo espiritual, dimensión en la cual la dignidad de todos los seres humanos es igual

(para los cristianos), datada entre los siglos VI a. C. y V a. C. Se estima que esta fuente data de una época cercana a la caída del reino de Israel en el norte; sus autores serían los sacerdotes de Jerusalén. Se interesa por las genealogías, ritos, leyes y fechas (Recuperado de http://es.wikipedia.org/wiki/ Tradici $\%$ C3 $\%$ B3n_sacerdotal consultado 23-9-2010).

4. La Tradición yahvista (abreviada Y), de acuerdo con la Hipótesis documentaria, es una de las cuatro fuentes principales a partir de las cuales se escribieron los libros del Tanaj o Antiguo Testamento, datada entre los siglos X a. C. y IX a. C. Es la fuente más antigua, y sus relatos representan la mitad del Génesis y la primera mitad del Éxodo, además de fragmentos de Números. Sus autores suelen designar a Dios con el nombre Yahvé (o más bien YHWH); suelen describir a Dios con reacciones y actitudes humanas, como un Dios familiar y cercano (Recuperado de http://es.wikipedia.org/ wiki/Tradici $\%$ C3\%B3n_yahvista consultado 23-9-2010).

5. Quizá lo más escandaloso de la sexualidad y ante Dios. Sin embargo, el segundo relato de la creación de la mujer a partir de la costilla del varón, sí hace referencia a la creación de los sexos y los cuerpos. El gran problema de esta interpretación es que parece dejar solamente al alma la posibilidad de parecerse a Dios; de esta forma, discreta e implícitamente, se iguala el cuerpo masculino a la imagen de Dios, mientras que lo femenino, relacionado por excelencia con lo corporal y lo sexual, no tiene el privilegio de Adán de ser imagen espiritual y corporal de Dios (Agacinski 2005:116). Podemos reflexionar, a partir de este relato, en torno a la creación del género humano que existen muchas posibilidades de interpretación que pueden desembocar en una supuesta inferioridad de la mujer, del cuerpo humano y de la sexualidad, los cuales son señalados como causa y consecuencia del pecado y la muerte; mientras que es prácticamente imposible, a partir de estos relatos, inferir una inferioridad de lo masculino o de lo espiritual respecto de otras dimensiones integrantes del género humano.

En el Nuevo Testamento, nos encontramos con la nueva Eva en María de Nazaret. El papel determinante de María en la economía de la salvación se basa en que Jesucristo, al ser verdadero hombre, requiere de una natalidad, y la natalidad de Jesús requiere de la maternidad de María. El cuerpo de la 
mujer es el lugar donde Dios entra a la carne y al tiempo. Sin embargo, con el pasar de los años y el desarrollo de la comunidad cristiana, se fue desarrollando poco a poco una clara dualidad entre la primera mujer, Eva, causa del pecado y la caída del género humano (es decir de la caída de los varones), y su contraparte, María, a través de la cual este pecado encuentra redención. Para Orígenes de Alejandría, a través de María se ha liberado la debilidad del sexo femenino como causa de la caída; y para Ireneo de Lyon, el nudo de la desobediencia de Eva fue desanudado por la obediencia de María (Agacinski, 2005:100-109) María, desexuada gracias a la obra del Espíritu y el género humano en su totalidad, feminizado en el motivo del matrimonio de Cristo con su Iglesia, es el prototipo de mujer. Jesús de Nazareth, varón que ha asumido nuestra carne masculina después de pasar por la carne femenina, es el ideal al que debemos avanzar. La pareja original conyugal Adán-Eva, manchada por el necesario defecto de la sexualidad, ahora es sustituida por una nueva pareja humana desexuada, constituida por madre e hijo (Agacinski, 2005:97). De ese modo, la generación carnal, que necesita de las mujeres, se sustituye por un modelo de generación masculina autónoma, donde en el esquema de la encarnación se da una relación vertical del espíritu con la carne.

Ciertamente, mucho de lo que hoy en occidente consideramos como parte de nuestra visión de lo corporal, es herencia de la tradición grecorromana, y del cristianismo que se desarrolló dentro de esta tradición histórica. La obra de Peter Brown El cuerpo y la sociedad. Los hombres, las mujeres y la renuncia sexual en el cristianismo primitivo (1988) nos da insumos muy ricos para comprender los primeros momentos del cristianismo y su visión del cuerpo y la sexualidad, visiones que sin dudad alguna nos influyen áun hoy.

El autor Brown hace énfasis en la complejidad de los cambios sufridos en el mundo grecorromano cuando incursionó la nueva visión de mundo que traían los cristianos, que se ubicaron en una cultura con una percepción ya de por sí muy rica y compleja sobre el cuerpo. Hay que comprender que muchas de estas tradiciones sobre lo corporal no son viables en sus aplicaciones cotidianas, ya que respondían a visiones de mundo y a contextos de salvación muy diferentes a los que debemos priorizar hoy día.

Brown inicia su estudio aclarando el panorama respecto de la visión grecorromana sobre el cuerpo y la sexualidad. Aclara que en la antigüedad, la mortalidad era sumamente alta, por lo que era 
necesario que cada mujer tuviera varios hijos, y por lo tanto la sexualidad estaba fuertemente ligada a la necesidad de reproducción. A pesar de esto, la institución de la virginidad era altamente valorada en el mundo antiguo, siendo una opción de las élites, ya que sólo los filósofos y las jovencitas de las más altas familias podían acceder a la exuberancia de la virginidad consagrada. Esta institución era vista en el mundo antiguo no como el culmen de la entrega libre y el ideal humano, sino como una excentricidad ejemplar, necesaria para el desarrollo de lo religioso (Brown, 1988:22-25).

En el mundo grecorromano, el papel más débil era sin duda el de la mujer, que era una especie de varón fallido, lo opuesto del ideal humano, la dimensión húmeda $\mathrm{y}$ fría de la humanidad, de la cual los varones tenían que luchar por alejarse. Las enseñanzas médicas de Galeno demostraban esta inferioridad de la mujer. Por el contrario, los varones debían aplicar una suave violencia con los más débiles e inferiores, a saber las mujeres y los esclavos. La vida familiar y la institución del matrimonio no se consideraban como una unión de amor, sino como un serio contrato social, microcosmos que definía la continuidad de la sociedad romana (Brown 1988:30-36).

El problema de los peligros del placer sexual es algo que, sin duda alguna, estaba presente en la Roma antigua. La relación sexual era un momento casi patológico durante el cual los varones perdían el control de sí mismos, y donde las mujeres les robaban la energía que les permitía seguir siendo varones, corriendo el peligro de volverse afeminados. Esto era una causa más para promover la continencia sexual entre los más excéntricos y poderosos personajes. El acto sexual no era, sin embargo, algo totalmente malo para los romanos, sino extremadamente necesario que encerraba determinados peligros, y que los caballeros más educados podían controlar (Brown 1988:37-40)

Debemos tener cuidado de no sacar de todas estas advertencias la conclusión de que los hombres del siglo II estaban obsesionados por el miedo al sexo. Muy por el contrario, consideraban que el acto sexual era uno de los muchos aspectos de su vida que podian poner bajo su control mediante el buen sentido y la educación. Acomodados, bien ejercitados y alimentados, sabían cómo contrarrestar los peligros que pudieran acompañar a sus periódicos y sin lugar a dudas placenteros desembolsos de espiritu vital por medio de un régimen de dieta y ejercicio juiciosamente elegido... los caballeros preocupados por la salud, escribió Galeno, hacían el amor incluso cuando el acto no les reportaba ningún placer en especial (Brown 1988:40). 
Las mujeres tenían que soportar en el imperio romano múltiples humillaciones, menosprecios, dolores y otros padecimientos propios de su lugar como criaturas inferiores a los varones. Quedarse vírgenes era más bien un privilegio que les permitía huir de muchos sufrimientos. Los cristianos heredaron muchos rasgos de esta posición inferior de las mujeres, pero mejoraron un poco las condiciones de justicia para las mismas y promovieron la mitigación de varios de los rasgos más abrasivos de la vida matrimonial para ellas (Brown 1988, 48).

Podemos afirmar con Brown que el mundo grecorromano definitivamente no era el mundo del libertinaje que quizá se ha filtrado hasta nuestros días. ${ }^{5}$ Para Brown, el cristianismo tomó lo mejor de la ética gentil respecto del matrimonio, el cuerpo y la sexualidad, y resaltó una dimensión especial

la corporalidad grecorromana que podemos reconocer en nuestros días es la reconocida práctica de los grandes señores de tener relaciones sexuales con sus jóvenes sirvientes, tanto femeninos como masculinos. El autor Brown señala que esto se debe a que los cuerpos de los sirvientes eran propiedad absoluta de su señor y esto era socialmente aceptado en Roma (1988:44). Los cristianos rompen claramente con esta práctica al denunciar la doble moral romana que condena la infidelidad femenina mas no el adulterio masculino.

6. Es importante resaltar este detalle exegético. y novedosa: la renuncia absoluta con fines de salvación. Si bien los filósofos antiguos ya predicaban la superioridad del espíritu respecto del cuerpo, y a practicar el dominio de las pasiones corporales, los cristianos van más allá, como lo demuestra Clemente de Alejandría para quien el ideal cristiano es "no sentir en absoluto el deseo" (Clemente, Stromateis. Citado por Brown 1988, 56).

En medio de este amplio y complejo panorama grecorromano respecto del cuerpo y la sexualidad, nos encontramos con la otra vertiente de la cual bebe la tradición cristiana sobre este tema: el judaísmo. Para los hebreos, la noción fundamental de "pureza del corazón" era la que regía lo relacionado con lo corporal y el comportamiento social. Esta noción daba indicaciones acerca de cómo huir de la lascivia, la codicia y los celos, además de ser una regulación ética de carácter solamente masculino. Las mujeres no sólo no estaban llamadas a cumplir con las exigencias de la pureza del corazón, sino que suelen ser señaladas como causa de desviación (Brown 1988: 60-68).

En época de Jesús, la presencia de santos varones profetas, ascetas y asexuados era común y se les veía como líderes en cuanto al tema de esta pureza de corazón. Juan Bautista y su primo Jesús de Nazaret eran claros ejemplos de estos 
predicadores que renunciaban al matrimonio y se dedicaban a difundir mensajes sociales y morales que iban siempre primordialmente dirigidos a los varones: "Pero yo os digo que todo el que mira a una mujer para desearla, ya adulteró con ella en su corazón" (Cf. Mt $5,28)$ "Porque de dentro, del corazón de los hombres, proceden los pensamientos malos, fornicaciones, hurtos, homicidios" (Cf. Mc 7,21) (Brown, 1988:73)

Respecto de las enseñanzas del Nuevo Testamento en torno al cuerpo y la sexualidad, debemos recordar que Jesús siempre se refería al tema dentro de un horizonte de justicia, redefiniendo instituciones como el matrimonio, que en adelante no se concebirán desde el mero legalismo, sino que pasarán a ser una promesa. Por ejemplo, según la interpretación de Picado Gatjens, la indisolubilidad del matrimonio se basa principalmente en una premisa de justicia para con la mujer, antes que consideraciones históricas y jurídicas. Las innovaciones de Jesús en esta materia abarcan también una innovadora visión del celibato y la familia:

En Mt 19,10-12, Jesús arranca ( separa) el matrimonio de su mera necesidad "natural". Renunciando Él mismo al matrimonio, instituye el celibato como vocación posible y de golpe revaloriza de igual modo el matrimonio como vocación. A causa del Reino, el celibato y el matrimonio dejan de ser realidades naturales o fatalidades sufridas para reflejar el uno al otro, y el uno por el otro, a la gracia de Dios que hace posibles la libertad y la vocación humanas. (Picado, 2006:111)

Continuando con su análisis histórico del pensamiento cristiano, Agacinski recuerda que Pablo estipuló claramente que "No hay judío ni griego, no hay esclavo ni hombre libre, no hay macho ni hembra, porque todos vosotros no sois si no uno en Cristo Jesús." (Cf. Gal 3,28). Pero esta supresión de las desigualdades concernientes a lo sexual parece darse sólo en una dimensión espiritual. Pablo nunca abogó por la supresión del orden social, donde las mujeres siguieron sometidas a sus maridos y los esclavos a sus señores. La asimetría en las relaciones sexuales, se basa en la inminente cercanía del fin con la segunda venida de Cristo, y es estipulada claramente en 1 Cor 11,3: "Ahora bien, quiero que entiendan que Cristo es cabeza de todo hombre, mientras que el hombre es cabeza de la mujer y Dios es cabeza de Cristo" (Agacinski, 2005:59-61)

El análisis de Picado Gatjens es un poco más benévolo con $\mathrm{Pa}$ blo, y parte de una exégesis más estricta sobre los textos neotestamentarios. Para este autor, en Pablo el cuerpo y su sexualidad inherente nunca es algo trivial, y 
de nuevo la dignidad e importancia del cuerpo viene de su íntima relación con el Espíritu Santo que en él habita: "¿No sabéis que sois santuario de Dios y que el Espíritu Santo habita en vosotros?" (Cf. 1 Cor. 3,16). Esta aseveración de Pablo sobre la relevancia del cuerpo en relación con el Espíritu que se nos ha dado, sirve como base para construir una teología de la sexualidad que repudia la fornicación que viola el cuerpo, y por lo tanto corrompe el sentido original de la pertenencia del cristiano al Cuerpo de Cristo, garantía de libertad y de plenitud humana (Picado 2006:116).

El aparente rechazo de Pablo a lo corporal-carnal y su preferencia por la virginidad y el celibato, viene de la certeza que tiene el autor de que los y las vírgenes pueden dedicarse mejor a la construcción del Reino, ante la inminente segunda

Pablo y muchos otros de su generación estaban convencidos de que Jesucristo volvería en pocos años, y que el juicio se daría antes de que acabara su vida. Debido a esta certeza que tenían muchos de los creyentes en las primeras décadas del movimiento de Jesús, es comprensible que Pablo plantee cierto grado de repudio hacia la formación de familias y la procreación: esto no es necesario si la segunda venida de Jesús y el juicio están cerca, y por esta razón Pablo sugiere "Hermanos, permanezca cada cual ante Dios en la condición en que fue llamado" Cf. 1 Cor.7,24 (Picado 2006:117).

7. Nada es más sorprendente para un observa- venida de Cristo. ${ }^{6}$ El cuerpo en la teología paulina tiene sin duda una determinada dignidad, e importancia, ya que es la prefiguración de lo futuro, de la gloria que le aguarda al ser humano cuando pronto Cristo vuelva:

En las epístolas de Pablo se nos presenta el cuerpo humano como en una fotografía tomada a contraluz... perecedero, débil sembrado en ignominia (Cf. 2Cor 12,2)... el cuerpo en Pablo tenía mucho de "vasija de tierra". Pero ya brillaba en él de alguna forma el mismo espíritu que había sacado de la tumba el cuerpo inerte de Jesús: "Para que la vida de Jesús se manifieste también en nuestra carne mortal" (2Cor 4,11) (Brown 1988:77).

La dignidad del matrimonio, las uniones conyugales y la sexualidad en general en Pablo, vienen de la metáfora entre el amor conyugal y el amor de Cristo a la Iglesia, donde los matrimonios son signo de la presencia gozosa de Cristo. De esta misma dignidad están revestidos los célibes quienes en toda su vida consagrada ejemplifican la entrega de Cristo para con la Iglesia (Picado 2006:119).

Pablo tiene en su obra dos prioridades claras: por un lado la inminencia del fin de los tiempos y la pronta segunda venida de Jesucristo, y por otro lado la adaptación de la rígida moral judía a la 
diversa y un poco más abierta moral de los gentiles conversos. Considerando estas dos prioridades en la obra paulina, podemos decir que para Pablo lo más importante no es la renuncia absoluta a la sexualidad, sino que más bien la prioridad es el mantenimiento del orden familiar y social. La cercanía del Reino y la pronta vuelta de Cristo hacen que las comunidades judías tuvieran que preservar el orden social; y la compleja y polémica inserción de gentiles al cristianismo hizo que Pablo o sus discípulos posteriores, tuvieran que redactar normas para todas las comunidades de conversos que respondieran a estas tradiciones que los judíos no estaban dispuestos a variar dentro de la naciente Iglesia. Muchas de estas prácticas y tradiciones en torno al cuerpo, la sexualidad, el lugar de la mujer y la familia, que hoy leemos como enseñanzas homogéneas de Pablo, son en realidad fruto de un intenso proceso de debates y negociaciones ante la inesperada diversidad y amplitud de las nacientes comunidades cristianas a lo largo de todo el imperio.

El celibato y la continencia tanto para varones como para mujeres eran una gracia a la que no todos podían estar llamados. El matrimonio no era una gracia como sí lo era la castidad, y denotaba una ausencia de llamado total:
La gracia apostólica del celibato era algo demasiado precioso como para extenderse al total de la Iglesia... el matrimonio, lo mismo que la esclavitud doméstica era una vocación carente de encanto. No merecía demasiada atención mientras la época actual se deslizaba silenciosamente hacia su final. El propio acortamiento del tiempo muy pronto la suprimiría (Brown 1988:90).

A pesar de todo lo anterior, creo que podemos determinar que la sexualidad, lo corporal y las uniones conyugales en el Nuevo Testamento, nunca son algo negativo, pecaminoso o despreciable, sino que se revisten, al igual que todas las dimensiones humanas, de una dignidad venida de Cristo y del Espíritu Santo que habita en nosotros, aunque sin duda la diversidad de vocaciones, llamados y necesidades de la iglesia naciente, hacían que determinados personajes, con un llamado particular a la castidad y la abstinencia, fueran los que redactaran el itinerario moral. Problemas posteriores como la inferioridad de la mujer o la percepción negativa del cuerpo y la sexualidad vienen de interpretaciones dadas por determinados contextos sociales, que ignoraron parte de la enseñanza de Jesús, o no supieron discernir que las enseñanzas de Pablo respondían a un momento histórico específico, donde la cercanía del Reino y el patriarcado vigente ocultaban 
la relevancia del papel de la mujer. Recordemos que un análisis detallado de las relaciones del Jesús histórico con sus seguidoras, revela la dignidad y el papel de las mujeres en la comunidad original, al punto de que ellas fueron testigos primordiales de la pasión y testigos primeros de la resurrección.

En torno al tema del varón, la mujer, el cuerpo y la sexualidad en la Biblia, se revela que, al menos en el desarrollo histórico del cristianismo, existe un gran drama en el cual se ha visto inmersa la humanidad desde que estos grandes mitos judeocristianos fueron construidos: la mujer, y sus dimensiones básicas inherentes, sexo y corporalidad, separan al varón de Dios, y por la falta cometida por ella se les condena a ellos y a sus descendientes a dos castigos contrapuestos pero relacionados que son la muerte y la necesidad de la reproducción carnal. Posteriormente, la humanidad dividida por su sexuación, da lugar a un proceso de cristiano de redención que no necesita de sexualidad para producir vida, como sí lo necesitamos los hijos de Eva (Agacinski , 2005:247).

A través de esta lectura descubrimos que existe una relación terriblemente contradictoria en la historia de las ideas judeocristianas respecto del cuerpo, la sexualidad y la mujer que les contiene y les define. Esta contradicción se da porque estas categorías dan al mismo tiempo vida y muerte, ya que nos definen como género humano con la dignidad de criaturas de Dios, y al mismo tiempo nos condenan a los pesares de la vida terrena. Es necesario resaltar también la diversidad de significados, comunidades y vivencias respecto del cuerpo, la sexualidad y la renuncia a los mismos en el cristianismo primitivo, y por lo tanto no es posible aplicar visiones reduccionistas respecto de este tema. ${ }^{7}$

En el siguiente apartado veremos cómo todo este desarrollo histórico de ideas sobre el cuerpo y la sexualidad se manifiesta en las orientaciones actuales de la teología ante el contexto y las exigencias que la situación moderna plantea sobre el tema del cuerpo.

dor de las iglesias cristianas del siglo II que la diversidad de significados que ya se había aglomerado en torno al hecho mudo de la renuncia sexual... los diversos cristianismos que ahora se encuentran pulcramente, uno al lado de otro en las bibliotecas de las estanterías de las bibliotecas modernas eran a menudo desconocidos entre sí en aquel tiempo. Cada uno de ellos delataba la presencia silenciosa de su paisaje social y religioso característico (Brown 1988:100).

8. El teólogo bíblico R. May aclara el pano- 


\section{Enseñanzas de la tradición eclesial sobre cuerpo y sexualidad ${ }^{8}$}

Para efecto del análisis crítico de las enseñanzas del magisterio católico, asumiré la siguiente premisa:

rama sobre las bases éticas de las Iglesias y movimientos cristianos en la actualidad, aclarando que existen dos vertientes históricas actuales claras. Por un lado la ética tradicional protestante se basa en la Ley de Cristo, en su Sola gratia, que se basa en el imperativo de la gracia y la libertad que Dios le da al ser humano; solamente por medio de la gracia de Cristo, el ser humano se salva. El paradigma protestante tiene la ventaja de que se centra en la libertad humana, pero esta ventaja le hace caer en el peligro del individualismo y en la pérdida de la dimensión histórica de la tradición cristiana. May también señala otro problema recurrente respecto de la tradición ética protestante la cual tiene un fuerte énfasis en la pecaminosidad del ser humano, paralizándole y coartando sus iniciativas (R. May 2004:100-102).

Por otro lado, tenemos la tradición católica se centra en el concepto de Ley Natural, ley venida de Dios, ley que debe ser adoptada por el hombre. Lo natural se corresponde con lo ético. May señala que el hecho de que esta Ley Natural sea una para la humanidad revelada por Dios, y nos ofrece criterios para defender la unidad y la dignidad de toda la humanidad a pesar de las diferencias culturales, y para la unidad de las iglesias y la cultura. Sin embargo, existen también muchas críticas a este paradigma ético de Ley Natural. Su carácter inmutable limita en cierto modo el libre actuar del ser humano y corre el grave peligro de confundir arreglos históricos y culturales con leyes inmutables sobrenaturales (May, 2004:104-105). Para efectos de la presente investigación procuraré reflexionar a partir de los aportes de ambos paradigmas e intentaré aprender de las críticas planteadas para ofrecer un intento la herencia de la tradición católica ofrece una visión pertinente y un diagnóstico eficaz en su magisterio sobre problemas relacionadas con el cuerpo y la sexualidad; pero estas premisas teológicas derivan en conclusiones y aplicaciones prácticas realmente desviadas de las exigencias de la realidad moderna del cuerpo y la sexualidad.

Reseñaré, pues, algunas de las más relevantes enseñanzas teológicas católicas actuales respecto del cuerpo y la sexualidad. Estas enseñanzas siempre parten de la premisa de la dignidad humana, venida del hecho de ser imagen de Dios. Afirma el Concilio Vaticano II:

La dignidad de la persona humana se hace cada vez más clara en la conciencia de los hombres de nuestro tiempo, y aumenta el número de quienes exigen que el hombre en su actuación goce y use de su propio criterio y de una libertad responsable, no movido por coacción, sino guiado por la conciencia del deber (Dignitatis Humanae, 1).

La encíclica Human Vitae de Pablo VI, respecto de la natalidad humana, parte de un análisis justo de los problemas médicos, demográficos y socioeconómicos de la

de respuesta sobre el tema del cuerpo y la sexualidad que responda a la tradición de las iglesias y la libertad humana.

9. Como nota subjetiva, deseo señalar que 
sociedad contemporánea (Human Vitae 2-3) y de una grandiosa definición del amor conyugal como auténticamente humano, pleno, fiel y fecundo (Human Vitae 9). Sin embargo, creo que no responde a la especificidad de la situación de millones de parejas humanas hoy, y de muchas culturas evangelizadas que no encuentran respuesta en este documento a su dignidad humana, cultural y corporal.

Sibien en la actualidad las enseñanzas de la iglesia nos dicen que lo primordial en las relaciones sexuales conyugales es el bienestar de los esposos, la encíclica nos recuerda que la unión matrimonial debe quedar abierta a la transmisión de la vida y no se puede desligar de sus dos significados: el unitivo y el procreador (Human Vitae 11-12). Al respecto de las anteriores consideraciones de la encíclica de Pablo VI, nos aclara Juan Pablo II:

El acto conyugal "significa" no sólo el amor, sino también la fecundidad potencial, y por esto no puede ser privado de su pleno y adecuado significado mediante intervenciones artificiales. En el acto conyugal no es licito separar artificialmente el significado unitivo del significado procreador, porque uno y otro pertenecen a la verdad intima del acto conyugal: uno se realiza justamente con el otro y, en cierto sentido, el uno a través de otro. Por lo tanto en este caso el acto conyugal, privado de su verdad interior, al ser privado artificialmente de su capacidad procreadora, deja también de ser acto de amor. (Juan Pablo II 2007:738)

Respecto de lo anterior, no niego la dimensión integral de la enseñanza de la Iglesia respecto del amor sexual mostrado en estas referencias del magisterio, ni discutiré si sus enseñanzas contradicen o no un sentido auténtico de libertad humana en la cultura actual. Lo que sí es imposible negar, es que las enseñanzas anteriores no abarcan ni responden a la especificidad médica, social, cultural, económica de muchos bautizados hoy. Y afirmo que cerrar la puerta a la especificidad humana y cultural de determinados creyentes, es ir en contra de su dignidad personal y social.

Una reflexión similar merece el tema de la castidad y la virginidad de los ministros de la Iglesia. Sin duda alguna, el celibato es un tesoro invaluable para la tradición católica. Por ejemplo, San Daniel Comboni no habría podido recorrer toda África con esposa e hijos; o la beata Teresa de Calcuta no habría podido realizar su obra de amor y esperanza si se hubiera casado en su natal Albania. El hecho de que los ministros y demás personas consagradas renuncien a su dimensión sexual y afectiva en el matrimonio, y a hacerse "eunucos 
a sí mismos por el Reino de los Cielos" (Cf. Mt 19,12) es un tesoro ejemplar sobre la entrega libre de amor a la comunidad eclesial y hacia los demás. Pero la especificidad humana de cada ministro, y las necesidades específicas de muchas comunidades, exige repensar los alcances de esta libertad y de esta entrega, que más bien puede ser contraproducente en términos pastorales. No digo lo anterior porque se debe renunciar al tesoro de la castidad y la virginidad de los ministros y demás hermanos consagrados, dejando por la libre esta tradición, sino porque la experiencia de nuestras comunidades muestra que esta práctica no es valorada ni seguida en su dimensión integral por muchos fieles y ministros, lo cual exige que, desde la particularidad y especificidad de cada sociedad, cultura y persona, se valoren los alcances reales de esta tradición.

La voluminosa obra Teología del cuerpo. Teología del sexo de la masculinidad y la feminidad compila diversas enseñanzas del papa Juan Pablo II, y ofrece una amplia visión panorámica sobre los temas que tratamos.

La obra del papa inicia enfatizando la unidad originaria del hombre y la mujer, basándose en un magistral análisis exegético que no deja lugar a dudas respecto de la unidad en la dignidad del varón y la mujer, y tocan temas álgidos como el de la vergüenza ante la desnudez que viene como consecuencia del pecado. Si antes del pecado los humanos no tenían vergüenza, entonces la vergüenza por la desnudez es un problema de la aceptación del yo según su justo valor frente al otro (Juan Pablo II 2007:103).

Esta vergüenza original es el fundamento antropológico y teológico que el papa esboza para iniciar su doctrina sobre el tema específico del cuerpo, lo corporal, la carne. Esta vergüenza "no se explica en el cuerpo mismo, en la sexualidad somática de ambos, si no que se remonta a las transformaciones más profundas sufridas por el espíritu humano." (Juan Pablo II, 2007:221). El problema entonces no se encuentra en el cuerpo humano, es la carne en sí, sino en la consciencia humana que, dañada por el pecado hace perder la libertad interior de donación mutua entre hombre y mujer en la sexualidad matrimonial, creando así la concupiscencia de la carne. Para Juan Pablo II, el cuerpo y el sexo no son malos en sí, sino que los hace malos la consciencia humana y los pensamientos de concupiscencia. La limitación de la sexualidad humana al ámbito matrimonial se basa tanto en la doctrina del análisis de la antropología teológica del génesis, como en un análisis de los discursos de Cristo en torno al adulterio y el matrimonio. Lo fundamental 
es que el matrimonio es una libre y plena entrega mutua del don de sí, y por lo tanto constituye el único ámbito en el cual la sexualidad se ve libre de la concupiscencia (Juan Pablo II 2007:232).

En un principio, tienen bastante sentido las enseñanzas de la iglesia a través del papa sobre el matrimonio y la sexualidad. Realmente, la dimensión integral que implica el sexo humano necesita de una institución fuerte, de un compromiso, de una mutua entrega, para que la sexualidad cumpla con un verdadero papel de bienestar humano. Surgen aquí dos preguntas: ¿solamente el matrimonio garantiza el compromiso humano necesario para una vivencia segura e integral de la sexualidad? Y por otro lado, ihacemos referencia solamente a las relaciones sexuales genitales con fines reproductivos al tocar este tema, o también abarcamos otras formas de sexualidad inherentes a la diversidad humana?

Una reflexión similar amerita las enseñanzas de la Iglesia acerca de la homosexualidad. En pocas palabras, la congregación para la doctrina de la fe enseña que la condición psíquica de la homosexualidad no es pecado, pero el ejercicio de esta condición, sobre todo el ejercicio de la sexualidad, sí lo es:

La Congregación tiene en cuenta la distinción comúnmente hecha entre condición o tendencia homosexual $y$ actos homosexuales... Sin embargo, en la discusión que siguió a la publicación de la Declaración, se propusieron unas interpretaciones excesivamente benévolas de la condición homosexual misma, hasta el punto de que alguno se atrevió incluso a definirla indiferente o, sin más, buena. Es necesario precisar, por el contrario, que la particular inclinación de la persona homosexual, aunque en sí no sea pecado, constituye sin embargo una tendencia, más o menos fuerte, hacia un comportamiento intrínsecamente malo desde el punto de vista moral. Por este motivo la inclinación misma debe ser considerada como objetivamente desordenada. (Carta a los obispos de la Iglesia Católica sobre la atención pastoral a las personas homosexuales, 3-4)

Esta perspectiva es profundamente paradójica, ya que acepta una condición humana sin permitirle ejercer su necesaria diversidad y libertad integral, ya que la homosexualidad no es pecado, pero su ejercicio sí lo es; muchas acciones humanas específicas le son prohibidas a los homosexuales, puesto que se da por sentado que, al ejercer ciertas acciones, se las estará impregnando de homosexualidad. La Iglesia no sólo se refiere a que el homosexual no puede ejercer su sexualidad, sino muchas otras acciones como la educación de niños, la convivencia con otros iguales, o el acceso a derechos civiles como 
el crédito y la herencia de bienes entre parejas.

Juan Pablo II continúa sus reflexiones sobre la dignidad humana alcanzando el horizonte escatológico, ya que debemos recordar que la resurrección de los cuerpos en un futuro celeste, es revelada por Jesús en su discusión con los saduceos (Cf. Mt 22,25-29), que deja ver que en "otro siglo" es decir, en un futuro escatológico, los cuerpos permanecerán en sexos diferenciados, pero no continuarán practicando la sexualidad relacionada con la fecundidad (Juan Pablo II, 2007:429). Esto nos plantea nuevas preguntas. Afirmada la dignidad del cuerpo humano que alcanza inclusive horizontes escatológicos, ¿no debemos prefigurar desde ahora un esfuerzo por dignificar miles de cuerpos humanos que sufren situaciones de violencia, anulación? Los esfuerzos de la Iglesia hoy, al menos en cuanto a los discursos teológicos, parece ir en buen sentido.

El magisterio del Papa Benedicto XVI sigue esta misma línea, una fuerte afirmación de la dignidad y la vida humana, que se debe concretar en una sexualidad responsable e integral que sólo puede ser tal en la donación libre y total que ofrece la institución del matrimonio.

El hombre es realmente él mismo cuando cuerpo y alma forman una unidad íntima... ni el cuerpo ni el espíritu aman por sí solos: es el hombre, la persona, la que ama como criatura unitaria, de la cual forman parte el cuerpo y el alma... Si se elimina esta unidad, se pierde el valor de la persona y se cae en el grave peligro de considerar el cuerpo como un objeto que se puede comprar o vender (Deus Caritas Est, 5).

Sin embargo, a lo largo de toda esta obra, nos encontramos con un mismo problema: una deficiente lectura de la diversidad de la realidad; un mensaje pertinente que se pierde por problemas de comunicación y prácticas pastorales concretas y eficaces; una absoluta y completa ausencia de diálogo con el mundo o con los fieles; una homogenización del género humano que no responde a las grandes diferencias y desigualdades del mundo actual. ${ }^{9}$ El error de los cristianos

me es imposible, como antropólogo social, decir sencillamente que los católicos, o los cristianos, se equivocan al defender un supuesto derecho natural, pues no es más que una creación humana. Desde una perspectiva teológica, antropológica, hermenéutica, mítica, la cosmovisión cristiana reconoce y explica maravillosamente un orden de mundo surgido desde un ser superior, que guía la vida de los creyentes desde una perspectiva de libertad. Sin embargo, me es imposible tolerar como teólogo la ausencia de diálogo con aquellos que han decidido, con la libertad que el mismo Dios le dio, no compartir esta cosmovisión.

10. LeBretón tiene especial interés en desentra- 
hoy no está tanto en tener una visión errada del mundo, ni en ofrecer opciones imposibles respecto de la realidad actual. El error más notable se encuentra en la forma de comunicarse y dialogar con las diversas cosmovisiones actuales, tanto entre los creyentes de cualquier religión, como entre los no creyentes y los indiferentes.

La diversidad cultural y los logros civiles contemporáneos no son un ataque directo a la hegemonía o a las enseñanzas eclesiales, sino que son dimensiones que ofrecen nuevos caminos por los cuales muchos seres humanos han decidido transitar, caminos en los cuales es necesario también encontrar el amor de Dios y en los cuales se puede aprender muchas posibilidades de desarrollo humano; nuevas formas de definir y reencontrar el misterio del amor de Jesús.

Esto último tampoco quiere decir que se debe aceptar sin más todos los elementos del mundo moderno, porque sin duda alguna, en muchos sitios del mismo, no se construye una humanidad mejor, sino que se desarrolla una verdadera cultura de muerte. Por ejemplo, Torres Queiruga se centra en un elemento álgido específico respecto de este tema como lo es la ciencia genética. Ésta no ataca a nuestra concepción de Dios y del mundo, sino que señala nuevos caminos para encontrarle (Torres, 2000:182).
Quizá debemos retomar esta premisa que ofrece este autor. La diversidad de cuerpos, sexualidades y culturas no contraría los designios de Dios, sino que ofrece nuevas formas de llegar a Él.

\section{Consideraciones sobre algunos problemas del cuerpo y la sexualidad en el mundo moderno}

Seguiré las orientaciones de David Le Breton en su obra Antropología del cuerpo y modernidad (2000) como marco conceptual y de referencia para pensar muchos problemas interesantes que se presentan al pensar en la situación del cuerpo en tiempos modernos.

Le Breton señala que los orígenes de nuestra visión de mundo en occidente actual, basados en el renacimiento, el giro epistemológico copernicano y el cartesianismo de Descartes, ciertamente colocaron de nuevo al ser humano en el centro del universo. Pero al mismo tiempo, procesos como la visión mecánica y matemática del mundo tuvieron un resultado adverso en varios sentidos respecto del cuerpo humano. El racionalismo hace que la naturaleza sea ahora un conjunto impersonal de leyes por descubrir, donde el cuerpo y sus sentidos son ineficaces para descubrir esta realidad, son fuente de engaño y sospechas, 
y el objetivo de la ciencia es ahora superar lo que percibimos con nuestro cuerpo. El dualismo cartesiano entre pensamiento y cuerpo, coloca al pensamiento en primer lugar antes que cualquier realidad humana, evidentemente antes que la corporal, cogito ergo sum. El intento de Descartes también pasó por comparar el cuerpo con una máquina, hizo que el cuerpo se des-simbolizara, dando pie a paradigmas biomédicos muy vigentes hasta hoy donde el cuerpo es visto como una máquina que en ocasiones se descompone, carente de significados especiales, que debe repararse en cada una de sus partes por separado.

Basándose en esta visión de mundo de la modernidad que aún sigue vigente en occidente, hablar hoy del cuerpo implica necesariamente referirse a la ciencia y la técnica biomédica-anatómica, que se presenta como la única autorizada para descifrar el cuerpo, excluyendo todo posible saber popular sobre el mismo, y ofreciendo una visión confusa a todos los que no somos expertos en el mismo. Esta visión del cuerpo como máquina, como piezas separadas en la medicina actual conlleva, junto con grandes beneficios para muchas personas que han salvado su vida, a situaciones tales como la necesidad de tráfico de órganos y sustancias humanas, que ven las partes del cuerpo como si fueran refacciones de un automóvil Ford. ${ }^{10}$ (Le Breton, capítulo 3, 2002: 72-82)

Continuando con la reflexión sobre el cuerpo en la modernidad, Le Breton señala que en la actualidad existe un marcado dominio del sentido de la vista en la sociedad urbana contemporánea:

La mirada se convirtió en el sentido hegemónico de la modernidad, la proliferación de cámaras de video... muestra una derivación de las miradas hacia una función de vigilancia, de la que nada ni nadie escapan... más allá del ruido y de los olores desagradables, la experiencia sensorial del hombre de la ciudad se reduce, esencialmente a lo visual ( $\mathrm{Le}$ Bretón 2002:103).

Otros sentidos, como el oído, se reducen en la ciudad moderna a ruidos constantes y a músicas estridentes, mientras que el olfato es el

\footnotetext{
ñar ambivalencias en los paradigmas que analiza. Así dice al respecto de las relaciones entre ciencia y técnica con el cuerpo hoy: "La técnica y la ciencia contemporánea mantienen una relación asombrosamente ambivalente con el cuerpo: éste es su antimodelo, aquélla lo rodea, intenta desembarazarse de él, al mismo tiempo que intenta sin cesar duplicarlo con sus medios torpemente... la lucha contra el cuerpo despliega su estructura oculta, lo reprimido que lo sostenía: el temor a la muerte. Corregir el cuerpo, hacer de él una máquina es escapar de este plazo" (Le Breton 2002:81).

11. "En Costa Rica, el 20\% de los embarazos se
} 
más despreciable de los sentidos en la ciudad moderna, donde el hombre lucha constantemente contra todo aquello que huela, salvo en ciertas ocasiones relacionadas con el sentido del gusto, el cual se debe satisfacer con velocidad y efectividad a través de comidas y bebidas rápidas (Le Breton Capitulo5,2002:91-119).

Para finalizar respecto del cuerpo en la vida moderna, Le Breton señala que hoy sigue existiendo una visión casi gnóstica del mismo, donde constantemente intentamos huir de este molesto arraigo carnal. El cuerpo actualmente es objeto de un amplio mercado de cosméticos, productos para adelgazar y máquinas de ejercicios y para sentirse bien. Situaciones nuevas, como los embarazos fuera de la mujer con los modernos procesos de ectogénesis, la procreación sin sexualidad, los úteros ocasionales, y aún debates un poco lejanos como la clonación, reducen al ser humano a lo genético, a un conjunto de partes perfectibles, donde bajo cierto imaginario biológico, el hombre es sólo un epifenómeno, un simulacro de su propio cuerpo, y el comportamiento y las relaciones humanas, son una especie de emanación de la superficie del cuerpo (Le Breton, 2002 Capítulo 11,2002:217-249)

"Para las orientaciones técnicas y científicas de la modernidad, el cuerpo es un bosquejo, un borrador cuyos rendimientos hay que controlar y mejorar. $O$ bien suprimir para que haya mejor funcionalidad. Cuerpo al que el hombre le debe la precariedad y al que quiere volver impermeable a la vejez o a la muerte, al sufrimiento o a la enfermedad" (Le Breton, 2002:249).

Respecto de esta revisión que hace el autor Le Breton sobre el cuerpo en el mundo moderno, podemos rescatar un punto muy importante: el cuerpo y en general el ser humano hoy exige ser sensibilizado, exige una respuesta a la multiplicidad de significados e implicaciones que se desprenden del cuerpo y la sexualidad desde cada género, edad, cultura y condición socioeconómica.

Muchos problemas relacionados con el cuerpo, y con la dignidad humana que le es inherente, tienen que ver con lo antes estipulado por Le Breton. Gran número de embarazos de adolescentes que no tienen las condiciones fisiológicas, psíquicas y socioeconómicas para sostener una nueva vida; millones de mujeres y hombres con imágenes distorsionadas de sí mismos que recurren a la bulimia y la anorexia como forma de tener el cuerpo que desean y que nunca les satisface, así como la nueva pandemia de obesidad que reduce muchos años de salud y vida a millones de personas; y, por otro lado, nuevas formas de hedonismo que 
llevan a las personas a ejercitarse en extremo e inyectarse drogas y someterse a dolorosas operaciones para tener un cuerpo satisfactorio a los ojos de la sociedad; así como con los cuerpos degradados, aislados y destruidos por el consumo de drogas no sólo químicas, sino nuevas dependencias corporales como adicción al sexo, a la pornografía y a la violencia.

Existen otros cuerpos de muchos seres humanos que sufren no tanto por sus condiciones y decisiones sujetivas, sino más bien por las condiciones políticas, sociales y económicas de los contextos donde viven, como lo son los cuerpos torturados y encarcelados por buscar la libertad y la justicia en ciertos regímenes políticos; los cuerpos de los migrantes que caminan de sur a norte buscando sueños bajo terribles condiciones de inseguridad y discriminación; los cuerpos hacinados y encarcelados en las cárceles alrededor del mundo, muchas veces sin una aplicación pronta y adecuada de la justicia; también los cuerpos de mujeres y algunos hombres sometidos a la explotación sexual; y los millones de cuerpos de niños, mujeres y hombres que mueren de un hambre constante, causada por la falta de solidaridad que parece reinar en el mundo.

\section{Necesidades pendientes para liberar, emancipar y dignificar al ser humano hoy}

A la luz del recorrido que hemos realizado, podemos señalar varias necesidades y plantear propuestas para que la teología de hoy en nuestro contexto responda a las exigencias que plantean los seres humanos desde su corporeidad.

Partiré desde una reflexión metodológica y epistemológica para la teología hoy. Hemos observado, a través de los análisis de determinados autores, que la teología en todos sus ámbitos se ha escrito siempre, en su inmensa mayoría, por varones, consagrados, de edad avanzada y principalmente ubicados en el primer mundo. Evidentemente, esta postura del autor dificulta el diálogo y el tomar en cuenta la postura del "otro", que siempre es distinto por determinados atributos que le son dados por su corporalidad, ya sea otro femenino, joven, de piel negra u marrón, discapacitado, etc. La teología actual parece no preocuparse por el papel del autor y su lugar respecto del otro. Y el problema viene cuando la homogeneidad de los autores actuales de teología es tal, que se hace imposible responder a la diversidad inabarcable de cuerpos y 
culturas que conforman la comunidad cristiana.

De este problema metodológico se deriva un problema pastoral y teológico. Si no se asume la diversidad actual de culturas y seres humanos que conforman el cristianismo, no es posible dignificar, liberar y emancipar, que es el deseo de amor que imprimió Dios en toda su creación muy buena.

Ciertamente, en determinadas ocasiones, esta libertad humana respecto del cuerpo y sus relaciones con los otros, ha sido mal aprovechada y ha causado mucho mal. A pesar de las múltiples situaciones de pecado y cultura de muerte que se dan en varios locus de la cultura moderna, es necesario pensar que muchas de estas libertades y diversidades humanas son auténticas expresiones que merecen toda la dignidad que la sociedad civil y la religión pueden ofrecer. Esta diversidad y dignidad no puede recibir una respuesta adecuada por parte de la teología si solamente una pequeña porción homogénea de la humanidad tiene voz en la producción teológica.

Quiero señalar en este lugar el aporte de la teóloga J. May quien hace precisamente una aplicación metodológica y pastoral como la que describo. En su obra Corporeidad, una reflexión ética teológica, la teóloga ofrece una posibilidad ética y teológica en torno al cuerpo y la sexualidad, buscando una visión soñada que se base en la diversidad, la justicia, el amor y el espacio de cada ser humano y las culturas; y en la lucha por un futuro mejor basado en la resistencia individual y organizada contra la opresión diaria que sufren mujeres, jóvenes y otros seres humanos. (J. May 2010:69-75)

Sin embargo, una propuesta de este tipo pasa metodológicamente por una vivencia personal particular. La autora May asegura en su estudio que ella hace esta propuesta desde un horizonte de esperanza, sanación, perdón y reconciliación. Ella relata su experiencia personal como mujer en la cual sufrió una violación por parte de un poderoso líder social y religioso, lo cual constituyó un grave trauma para su cuerpo y su sexualidad. A través de esta experiencia ella obtuvo la fuerza para exigir una ética y una teología pertinente para las situaciones que sufren millones de personas hoy:

Al final de cuentas, todo ha sido doloroso, pero no sin esperanza... Esta y muchas otras experiencias propias y de otras personas me han inquietado en cuanto al papel de la $f e$, de la iglesia y del pastoral en el discernimiento ético y de la necesidad de trabajos pastorales para prevenir la violencia y para ayudar a las víctimas a descubrir posibili- 
dades de sanación y reconstrucción de sus vidas (J. May 2010:105).

Estas reflexiones, además de muy pertinentes en cuanto a su contenido teológico y pastoral, presentan una premisa metodológica y epistemológica particular; es el hecho de que la autora se coloca en su situación humana y desde ahí plantea sus propuestas. Los autores de teología deben saber leer no sólo sus contextos sino que también deben saber leer su propia situación humana y reconocer que escriben desde determinada situación de género y cultura, para lectores y comunidades diversas.

La tradición no está absolutamente mal, a pesar de sus problemas de diálogo con el contexto actual. Esta tradición cristiana de las principales iglesias ofrece una base teológica que da bases para dignificar, liberar y emancipar al ser humano. Pero claramente hace falta una praxis política real, exigencias concretas, acciones en contra de la discriminación de ciertos grupos socioculturales que representan la diversidad humana innegable de la sociedad actual.

Así pues, es necesario asumir un compromiso real por liberar y emancipar al ser humano integral, presente con particular importancia en su corporeidad. Pero ¿qué queremos decir cuando exigimos liberar? No se puede confundir el liberar y emancipar auténticamente desde el cristianismo con sencillo libertinaje, una especie de laissez faire, que más bien puede llevar a una mayor opresión y confusión en las relaciones humanas. Cuando exigimos liberar y emancipar, lo hacemos desde una perspectiva que implica liberarse de estructuras y leyes injustas impuestas desde diversas instituciones que atentan contra las posibilidades de desarro1lo integral del individuo.

No es sencillo encontrar una definición clara y eficaz de lo que significa liberación humana desde la tradición filosófica y teológica latinoamericana. Para los efectos del presente ensayo, quisiera tomar la propuesta de Hinkelammert, basado en el pasaje del Génesis sobre el sacrificio de Isaac por parte de su padre Abraham. Recordemos que en este pasaje, Abraham recibe la orden-ley de sacrificar a su hijo. Según el análisis exegético de Hinkelammert, no nos encontramos ante una prueba específica y aislada solicitada al patriarca Abraham por parte de Dios, sino que se trata de una tradición instituida entre los pueblos nómadas y pastoriles a los que pertenecía el Abraham. Entonces, nos encontramos ante una ley que sacrifica al ser humano, una ley injusta, que proclama la muerte en lugar de la vida. Al obedecer al ángel que le ordena no sacrificar a su hijo Isaac, el primer patriarca 
proclama que las leyes y estructuras injustas de este mundo, aunque aceptadas por la sociedad y la tradición, deben ser repensadas en favor de los seres humanos:

La sorpresa es que ahora aparece el Ángel de Dios, que pide a Abraham no sacrificar a su hijo. Pide violar la ley, pide una transgresión de la ley de Dios. Pide un acto dificil que va a confrontar a Abraham con toda su cultura... Lo que le pide el Ángel, es hacerse libre y ponerse encima de la ley. Abraham obedece. Por lo tanto no obedece a ninguna norma y ninguna ley. Al ser libre, Abraham es soberano frente a la ley (Hinkelammert 2000:16).

Pero es importante recordar que este pasaje del Antiguo Testamento, no significa nunca libertinaje, despreciar absolutamente la tradición, o dejar de lado las palabras de Dios transmitidas por la comunidad de Fe. Esta interpretación exegética particular del pasaje del sacrificio de Isaac, nos insta a repensar las leyes de nuestra cultura, y a hacer una opción clara a favor del ser humano, aun en contra de aquellas leyes arraigadas en la tradición, que implican la muerte del hombre y la mujer:

Esta afirmación de libertad, no es la afirmación de ninguna arbitrariedad frente a la ley. Abraham no es aquel que hace lo que le da la gana. Abraham es libre, no arbitrario, él afirma su libertad afirmando la vida, la vida de los otros y la suya. Por eso no sacrifica a su hijo sino que lo destina a la vida y por lo tanto a su propia libertad (Hinkelammert 2000:16).

Este mismo concepto de vida y libertad es el que deseo aplicar al reflexionar sobre la corporalidad, la sexualidad y el bienestar humano en general. No quiero abogar por el libertinaje sexual y la arbitrariedad en torno al propio cuerpo y el de los otros, sino que es necesario pensar siempre en el bienestar, la vida y el desarrollo integral del ser humano.

Este análisis exegético de Hinkelammert critica muchas aplicaciones de la ley natural estipulada como base de la moral católica actual. Reconocemos que mucha de la luz que nos da esta ley natural es buena, una auténtica búsqueda de la afirmación de la vida humana. Pero mucho de lo que hay en los alcances y aplicaciones de esta ley natural hoy es, sin duda alguna, tradición cultural que no permite emancipar auténticamente a muchos seres humanos hoy día. Es necesario discernir qué es cultura y qué es revelación, qué es odre y qué es vino al respecto de este tema, para que las mujeres, jóvenes $\mathrm{y}$ personas con distintas percepciones culturales del cuerpo, ocupen el espacio que merecen en las comunidades cristianas. Debemos 
conservar el corazón de la maravillosa herencia antropológica del cristianismo, pero descartando tradiciones culturales occidentales caducas que en la práctica contradicen una práctica auténtica de la libertad y la emancipación humana desde una perspectiva evangélica. Esta es una tarea muy compleja para la teología y la Iglesia hoy, que no puede sencillamente observando que más y más fieles pierda la esperanza y la fe por no sentirse acogidos por otros cristianos.

Respecto del tema de la mujer, su dignidad y su corporalidad, nos hemos encontrado con que una exégesis estricta tanto de los textos del Antiguo como del Nuevo Testamento, dignifica a la mujer y la coloca en igualdad a los varones. Tradiciones profundamente arraigadas a lo largo del mundo establecen la superioridad masculina en cuestiones prácticas, a pesar de la enseñanza de Jesucristo, que demuestra la igualdad y dignidad primordial de la mujer. Discusiones un poco más específicas y posteriores, como la validez o viabilidad de la ordenación sacerdotal femenina en la Iglesia Católica, son temas que van de la mano con la dignificación integral a nivel global de la mujer y su cuerpo, y aunque en algunos espacios de la sociedad civil se ha buscado una igualdad nominal para las mujeres, existen aún mentalidades, esquemas y tradiciones que son las verdaderas barreras por romper en el asunto de la inferioridad femenina en muchos momentos y lugares en la actualidad.

Otro problema indudable de la realidad actual es el de la sexualidad de los jóvenes y adolescentes. Según mi experiencia personal de investigación antropológica en el campo, esta es una realidad vigente ante la que no se puede seguir callando $\mathrm{u}$ ofreciendo medidas propias de una moral casuística. En primer lugar, hay que ceptar un secreto a voces: los jóvenes y adolescentes de hoy practican una sexualidad frecuente y con múltiples manifestaciones, desde las simples miradas, pensamientos, imágenes y roces, hasta la frecuente genitalidad con distintas parejas. Aceptar esta realidad cotidiana es el primer paso para abarcar los problemas que acarrea. La sexualidad practicada por muchos jóvenes y adolescentes actualmente carece de afectividad duradera, está marcada por una fuerte genitalización y, para empeorar el asunto, sigue siendo tratada por instituciones como las autoridades de educación o la iglesia como un tema tabú, del que no se puede hablar o discutir, a pesar de que está plenamente vigente. ${ }^{11}$

da en mujeres menores de 18 años, y el $80 \%$ de los embarazos no planificados en féminas de estas edades. En el 2009 resultaron 1434 
Abogar por la abstinencia hasta el matrimonio no es, desde cualquier punto de vista sociológico o educativo, una solución realista. Los jóvenes viven una sexualidad muy activa y muchos la seguirán viviendo de este modo, ya que es un tema profundamente arraigado en la cultura actual. Tampoco es adecuada una visión del problema puramente biomédica, que se centra en evitar posibles enfermedades de transmisión sexual y embarazos no planificados por medio de métodos anticonceptivos, dejando de lado la parte afectiva, psíquica y espiritual del ser humano. Ni la visión puramente biomédica ni la visión eclesial, toman en cuenta la realidad observada reiteradamente en las calles, donde los jóvenes carecen de los insumos educativos, culturales y económicos para vivir una sexualidad informada, firme afectivamente y segura ante embarazos no deseados y enfermedades.

Es necesario que la teología y la práctica pastoral acepten estas realidades, entrar en sincero diálogo con la ciencia y las autoridades civiles para lograr el fin de ofrecer verdaderas posibilidades

jóvenes embarazadas en 401 centros educativos; 27 de los colegios reportaron 313 casos. La mayor parte de estos casos se encuentra en el nivel de secundaria de las zonas marginales" Tomado de Diario La Nación, 27-9-2010.

12. Esta respuesta es dada por J. May en su obra de construir compromiso humano, descubrir la libertad auténtica que se da en la entrega y que exige preocupación auténtica por la vida del otro, bases para una práctica integral de la sexualidad. Aceptamos, junto con la Iglesia Católica, que la abstinencia, la fidelidad y la práctica de la sexualidad sólo dentro de una institución que provea el marco de seguridad necesario, como lo es el matrimonio, serían las mejores opciones para evitar muchos problemas relacionados con la sexualidad hoy. Pero los llamados de atención de la realidad nos hacen ver que esta vía es utópica, ya que millones de personas en las diversas culturas globales hoy practican una sexualidad que no corresponde con la visión planteada por la Iglesia.

Dentro de este mismo ámbito de problemas, pero relacionados claramente con una cultura de muerte, nos encontramos con situaciones como la sexualidad desordenada, el hedonismo que se manifiesta en el consumo de drogas, el tráfico internacional de personas para prostitución y la esclavización; son todos estos problemas de los cuerpos de millones de personas hoy que no encuentran una respuesta eficaz dentro de las Iglesias, y que son objeto de un discurso teológico separado de aplicaciones pastorales efectivas. De nuevo, negar y condenar estas 
situaciones no es una opción, sino que es necesario luchar efectivamente por una cultura de libertad y emancipación, donde cada cristiano, apoyado por su comunidad eclesial, se vea comprometido a socorrer a los que sufren estas situaciones de injusticia.

La homosexualidad es un delicado tema teológico y social, que necesita abrir aún muchas puertas y mentes hoy. El discurso eclesial, de aceptación y respeto hacia la comunidad homosexual, demuestra que existe ya al menos un portillo, pero con soluciones y salidas claramente insuficientes. La opción ofrecida, es decir el castramiento voluntario, demuestran una negación de los derechos de vivir la corporalidad, y un énfasis desmesurado en la dimensión genital del individuo por parte de las Iglesias. El homosexual puede serlo, ya que es su derecho y su condición psíquica, pero la Iglesia le solicita no vivir su condición desde lo sexual genital. Otras dimensiones integrales, como la afectividad, la visión de mundo y los derechos civiles, no parecen tener campo de discusión en la Iglesia. El problema es que los homosexuales no sólo están presentes con todas sus dimensiones humanas, sus problemas y sus derechos en las congregaciones cristianas actuales, sino que es innegable que muchos homosexuales son ordenados ministros en diferentes iglesias y comunidades cristianas. ${ }^{12}$ La solución no es la expulsión y el aislamiento, como se ha pretendido, sino la aceptación de la realidad de ese otro, que está ya aquí con nosotros, construyendo iglesia, sociedad y cultura, con nuevos problemas y nuevas propuestas, y responder auténticamente a la realidad exige que se abra discusión sobre el papel de los homosexuales en las comunidades cristianas, para liberar auténticamente a estas personas de muchas de las cadenas y silencios que la cultura actual les impone por una vivencia determinada de su corporalidad.

Otros problemas álgidos se dan respecto de diversidades innegables presentes en la iglesia y que no tienen derecho a existencia o participación plena dentro de la sociedad civil y la comunidad cristiana. Me refiero a los nuevos tipos de familia, conformadas por parejas de

\footnotetext{
antes mencionada, cuando ella hace la pregunta a un ministro de su comunidad acerca de cuándo la iglesia ordenará personas homosexuales. El ministro le responde "esta no es la pregunta correcta. La verdad es que ordenan personas homosexuales todos los años... la verdadera pregunta es ¿cuándo van a dejar de fingir que no ordenan homosexuales?" (May, 2010:95). Esta experiencia y realidad nos permite decir que el discernimiento ético a lo interno de las iglesias es un proceso complejo y con muchos obstáculos. Pero el primer paso debe ser reconocer la realidad para responder a ella.
} 
un solo sexo, por madres solas que deben sufrir el doble de las cargas económicas, emocionales y sociales debido a su condición de soledad. También familias conformadas por personas divorciadas. Todas estas nuevas conformaciones sociofamiliares pertenecen desde hace mucho tiempo a nuestras comunidades cristianas, pero su diversidad y sus derechos no encuentran respuesta adecuada en la Iglesia. Al igual que las personas homosexuales, el problema no es si se acepta, si se permite integrar y se abren las puertas a estas diversidades del género humano. El problema es que ya están activamente participando de nuestras comunidades cristianas, y en muchas ocasiones su auténtica condición humana es tachada de pecado sin que medie atenuación por sus consecuencias o su dignidad humana y sus derechos civiles.

\section{Conclusión}

Hemos reconocido a lo largo de este breve análisis dos tipos de leyes o convencionalismos culturales sobre el cuerpo humano. Son leyes como las aplicadas en la colonia penitenciaria metafórica de Kafka, leyes que dañan la integridad y la dignidad del cuerpo humano representado particularmente por su cuerpo; leyes-máquina obsoletas cuyo significado distorsionado pretende en el fondo corregir y encaminar determinado tipo de humanidad, pero que con el paso del tiempo se desvían de su objetivo original de justicia y libertad para convertirse en cadenas para el ser humano.

La primera de estas leyes es la ley de muchos grupos cristianos actualmente, ley considerada natural que reviste en determinadas aplicaciones prácticas de carácter cultural sospechosamente similares a determinadas prácticas occidentales-europeas sobre el cuerpo y la sociedad. Si bien esta ley natural moral cristiana tiene en el fondo una invaluable e inmutable enseñanza de dignidad y valor de la vida humana, en muchos momentos sus interpretaciones y alcances parecen contradecir las enseñanzas originarias de auténtica libertad humana. Hemos observado cómo la diversidad corporal y sexual particular de muchas mujeres, jóvenes y culturas se ven coartadas en su auténtica libertad por parte de enseñanzas y tradiciones cristianas.

Por otro lado, tenemos una segunda ley ofrecida como atractiva por la sociedad actual. Una ley basada en el hedonismo, lo rápido y pasajero, la satisfacción inmediata, el placer despreocupado que será mejor conforme tenga mayor costo monetario. Esta ley, claramente contraria a una auténtica libertad humana y a la dignidad integral del cuerpo y la persona, encuentra una fuerte condena en los pasajes 
de la enseñanza judeo-cristiana que demuestran que el verdadero amor y la verdadera belleza no son egoístas, sino que encuentran su culmen y significado en el bienestar integral de uno que encuentra la libertad de la entrega gratuita de entrega en el otro. Una teología y una iglesia que se encuentren ubicadas claramente en el corazón de la sociedad y que saben reconocer sus gozos y esperanzas, sus tristezas y angustias, deben condenar severamente estas prácticas culturales que llevan claramente a la muerte y a la denigración de lo humano, y tener un papel activo a través de un trabajo pastoral concreto que promueva la dignidad humana, la justicia y la libertad integral de los sujetos.

En el fondo de todas estas reflexiones sobre el cuerpo y la sexualidad, no hay otra cosa que una búsqueda profunda y sincera del amor. Ese amor descrito de forma inigualable y eternamente en el "Cantar de los Cantares", un amor que se basa en la entrega al otro, en la libertad que implica construir el bien para mi entorno, un amor que es sensual y espiritual al mismo tiempo. Este amor humano auténtico que construye, dignifica y es libre en la entrega, debe ser la base de toda teología que busque emancipar al cuerpo y al ser humano de las muchas cadenas que le atan hoy.

\section{Bibliografía}

Agacinski, M. (2005) Metafísica de los sexos. Masculinolfemenino en los orígenes del cristianismo. Ed. Akal, Madrid.

Benedicto XVI, Papa. (2005) Deus Caritas Est. Carta encíclica sobre el amor humano. [En línea] Disponible en: http:// www.vatican.va/holy_father/benedict_ xvi/encyclicals/documents Recuperado el 25-9-2010.

Brown, P. (1988) El cuerpo y la sociedad. Los hombres, las mujeres y la renuncia sexual en el cristianismo primitivo. Columbia University Press, Muchnik Editores, Barcelona.

Congregación para la doctrina de la fe. Carta a los obispos de la Iglesia Católica sobre la atención pastoral a las personas homosexuales. Roma, (1-10-1986) [En línea] Disponible en: http://www. pionet.org/Documentos/trato_past_ homo.htm Recuperado el 25-9-2010.

"Declaración Dignitatis Humanae. Sobre la libertad religiosa." En: Documentos completos del Vaticano II. (1966) Mensajero, Bilbao. Págs. 125-212

Eliade, M. (1972) Tratado de historia de las religiones. Ediciones Era, México D.F.

Hinkelammert, F. (2000) La fe de Abraham y el Edipo occidental. DEI, San José.

Juan Pablo II (2007) Teología del cuerpo: teología de la sexualidad humana: de la masculinidad y la feminidad. Promesa, San José.

Kafka, F. (1919) La colonia penitenciaria. (En línea) disponible en: www.librodot.com. Consultado el 2-9-2010. 
Le Breton, D. (2002) Antropología del cuerpo y modernidad. Nueva Visión, Buenos Aires.

May, R. (2004) Discernimiento moral. Una introducción a la ética cristiana. DEIUBLA. San José.

May, J. (2010) Corporeidad, una reflexión ético teológica. DEI-UBLA. San José.
Pablo VI, Papa. "Human Vitae" En: Las encíclicas del mundo moderno. (1969) Editorial Bruguera, Barcelona. Págs. 623-666.

Torres Queiruga (2000) El problema de Dios en la modernidad. Verbo Divino, Santander. 
